\title{
Comparison of two electronic hand hygiene monitoring systems in promoting hand hygiene of healthcare workers in the intensive care unit
}

Xiao Zhong ${ }^{1 *}$ D, Dong-Li Wang ${ }^{2}$, Li-Hua Xiao ${ }^{1}$, Lan-Fang Mo ${ }^{1}$, Qing-Fei Wu ${ }^{1}$, Yan-Wei Chen ${ }^{1}$ and Xiao-Feng Luo ${ }^{1}$

\begin{abstract}
Background: Hand hygiene $(\mathrm{HH})$ is the cornerstone of infection control, and the promotion of $\mathrm{HH}$ is the focus of the world. The study aims to compare the role of two different types of electronic hand hygiene monitoring systems (EHHMSs) in promoting HH of healthcare workers (HCWs) in the intensive care unit (ICU).

Methods: In a 16-bed ICU of a general tertiary hospital in Shenzhen, the research was divided into three stages with interrupted time series (ITS) design. In the first stage, the direct observation method was used to monitor and feed back the HH compliance rate of HCWs monthly. In the second stage, the type1 EHHMS was applied to monitor and feed back the individual number of HH events monthly. In the third stage, the type2 EHHMS with a function of instant reminder and feedback was employed, and the personal $\mathrm{HH}$ compliance rates were fed back monthly. Meanwhile, direct observation continued in the last two stages.

Results: In the second stage, The HH compliance rate increased. However, there was no significant difference in the trajectory of the rate compared with the first stage. In the first month of the third stage, the HH compliance rate increased by $12.324 \%$ immediately and then ascended by $1.242 \%$ over time. The number of $\mathrm{HH}$ events per bed day and HH products' consumption per bed day were consistent with the change of $\mathrm{HH}$ compliance rate observed.

Conclusion: Monitoring and feedback can improve the HH of HCWs. The EHHMS, with the function of real-time reminders and feedback, has a more noticeable effect on promoting $\mathrm{HH}$.
\end{abstract}

Keywords: Hand hygiene, Electronic hand hygiene monitoring systems, Interrupted time series analyse, Infection prevent and control, Reminder and feedback

\footnotetext{
*Correspondence: 187197283@qq.com

'Department of Nosocomial Infection Control, Shenzhen Hospital, University of Chinese Academy of Sciences, Shenzhen 518106, Guangdong, China

Full list of author information is available at the end of the article
}

(c) The Author(s). 2021 Open Access This article is licensed under a Creative Commons Attribution 4.0 International License, which permits use, sharing, adaptation, distribution and reproduction in any medium or format, as long as you give appropriate credit to the original author(s) and the source, provide a link to the Creative Commons licence, and indicate if changes were made. The images or other third party material in this article are included in the article's Creative Commons licence, unless indicated otherwise in a credit line to the material. If material is not included in the article's Creative Commons licence and your intended use is not permitted by statutory regulation or exceeds the permitted use, you will need to obtain permission directly from the copyright holder. To view a copy of this licence, visit http://creativecommons.org/licenses/by/4.0/. The Creative Commons Public Domain Dedication waiver (http://creativecommons.org/publicdomain/zero/1.0/) applies to the data made available in this article, unless otherwise stated in a credit line to the data. 


\section{Background}

Hand hygiene is currently recognized as the cornerstone of healthcare-associated infection (HAI) control [1]. It can effectively prevent the hands from becoming the vectors of HAIs pathogens, consequently reducing the occurrence of HAIs [2-5]. In 2009 the WHO issued five critical HH moments [4]: 1. Before contact with the patient; 2. Before cleaning and aseptic operation; 3 . After a body fluid exposure risk; 4. After contact with the patient; 5. After touching the patient's surroundings. These five $\mathrm{HH}$ moments are the principles that every $\mathrm{HCW}$ should follow in their work. However, the low HH compliance of HCWs has been a global problem [6]. The overall median $\mathrm{HH}$ compliance rate was $40 \%$, and the $\mathrm{HH}$ compliance rates were lower in ICU (30-40\%) than in other settings $(50-60 \%)$, which was reported by a systematic review contained 96 studies [7]. The low $\mathrm{HH}$ compliance rate was associated with sustained work stress faced by HCWs in the complex modern healthcare environment [8]. Therefore, HH's promotion among HCWs is a challenge and focus for different levels and kinds of medical establishments.

Monitoring \& feedback is the most commonly used measure to promote $\mathrm{HH}$ among HCWs, compared with training, education, and reminders [9], which have proved to be one of the useful measures among the multimodal measures for $\mathrm{HH}$ promotion [10]. At present, direct observation is still the golden standard of $\mathrm{HH}$ monitoring. Even though it has many defects [11, 12]: time and labor consuming, an insufficient number of hand hygiene events (HHEs) observed, Hawthorne effect, and observer bias $[4,13]$. To solve or reduce the direct observation method's shortcomings, a new $\mathrm{HH}$ monitoring tool, namely the EHHMS, has been gradually developed in recent years. The EHHMS can be defined as the auxiliary system of direct observation or the automatic electronic system that can continuously collect data such as $\mathrm{HH}$ moments, HHEs, or $\mathrm{HH}$ product consumption. It can count, analyze, and feed back the data. Such as dispenser and handwashing counting systems, Wi-Fi identity badges modified to detect alcohol vapors, radiofrequency identification badge systems, and automated $\mathrm{HH}$ monitoring networks [14-16].

Some infection control experts have reported the applications of EHHMSs to promote HH of HCWs. For example, Edmisten $\mathrm{C}$ et al. [12] applied EHHMS in three community hospitals to monitor and improve the $\mathrm{HH}$ of HCWs to keep the $\mathrm{HH}$ compliance rate above $85 \%$. Pong $S$ et al. [17] used the EHHMS with a reminder function to monitor the $\mathrm{HH}$ of HCWs entering and leaving the wards and found that the number of HHEs doubled after the adoption of the system, and it decreased by $0.18 \%$ per week after the removal of the system. However, different kinds of EHHMSs may play different roles in the promotion of HCWs' HH. Recently, few articles have compared the effects of different EHHMSs in promoting $\mathrm{HH}$ among HCWs. Therefore, it was necessary to explore what kinds of EHHMSs could better promote the $\mathrm{HH}$ of HCWs.

\section{Methods \\ Study object and design}

This study was carried out in a general ICU of a tertiary hospital with 1350 open beds in Guangming District, Shenzhen city, Guangdong province, China. The ICU has 16 beds and $46 \mathrm{HCWs}$, including 11 doctors and 35 nurses. The mean ages of HCWs were $32.5 \pm 6.8$ years. Five of the 35 nurses were male, and all the doctors were male. This study was a quality improvement activity and had been approved by the hospital ethics committee. All HCWs in the ICU were selected as study subjects, and informed consent was signed. Those who resigned or transferred to another department would automatically withdraw from the study, and recruits would need to be retrained and sign informed consent.

To compare the effects of two kinds of EHHMSs, from March 2018 to December 2019, our hospital successively used two different EHHMSs to monitor the $\mathrm{HH}$ of HCWs in the ICU. Meanwhile, the direct observation method was used to evaluate the effect of two EHHMSs. The study adopted the method of ITS design, which was divided into three stages. In the first stage: from March 2017 to February 2018, direct observation was used to monitor the HH of ICU HCWs according to WHO's five $\mathrm{HH}$ moments. The total $\mathrm{HH}$ compliance rate was reported to the department monthly. In the second stage: from March 2018 to January 2019, the type1 EHHMS was used to monitor the HH of ICU HCWs. The system can track the HHEs and the consumption of alcoholbased hand rubs (ABHRs) \& liquid soaps but does not recognize $\mathrm{HH}$ moments. The ranking of individual HHEs per bed day was fed back to the department every month. In the third stage: from February 2019 to December 2019, the type2 EHHMS was used to monitor the $\mathrm{HH}$ of ICU HCWs. The system can automatically identify the $\mathrm{HH}$ indicators, including before and after contacting the patient, after touching the patient's surrounding environment and objects, and immediately reminded the HCWs to perform $\mathrm{HH}$. The personal $\mathrm{HH}$ compliance rate ranking was fed back to the department monthly. In the second and third stages, direct observation continued to monitor the HH of HCWs. For exploring the effects of two EHHMSs on HH of ICU HCWs, the variation trend of HCW's $\mathrm{HH}$ compliance rate, the HHEs, and the consumption of ABHRs \& liquid soaps were compared. During these three stages, all other infection control measures remained unchanged, nor did any other form of $\mathrm{HH}$ promotion movement. 


\section{The direct observational method}

Two observers, composed of infection control professionals, with more than 10 years of work experience and an average age of 35 years, had been trained and educated repeatedly according to the principles of "My five moments for hand hygiene" in advance. Kappa statistics had been performed to ensure that their inter-observer compliance reached over $75 \%$. Then a detailed observation schedule that specified sessions for observation was formulated. Each session lasted $30 \mathrm{~min}$, including both busy and free periods. The two observers were randomly assigned to observe four busy and free periods each month for 4 h. From March 2017 to December 2019, the two observers used the mobile phone APP (HH observation auxiliary system) to perform the observations according to the observation scheme. The APP could reduce the Hawthorne effect compared with the conventional paper observation table [16]. Observers in ICU wards used this APP instead of paper observation forms to observe and record the $\mathrm{HH}$ of HCWs, which was relatively hidden and not easily detected. When the HCWs noticed the observers' presence, they assumed the observers were looking at the phone. Because the observers were fixed for a long time, it was hard to avoid detection. When in doubt, observers explained that they were examining other items. Through this unobtrusive observation, the Hawthorne effect brought by the observers was avoided as much as possible. The total $\mathrm{HH}$ compliance rate was fed back to the HCWs every month.

\section{The type1 EHHMS}

From March 2018 to January 2019, the type1 EHHMS was used to monitor the $\mathrm{HH}$ of ICU HCWs. An additional file shows the technical parameters of type1 EHHMS (Additional file 1: The technical parameters. Part 1.). The system is a monitoring system for HHEs of HCWs. ABHRs or liquid soap dispensers with sensors were installed near every ICU bed and sink, and identification badges were worn on the chest of HCWs. When HCWs placed their hands on the dispensers' outlet, the outlets would spray the liquid automatically, and the badges would receive a signal from the sensor to record the HHEs. The sensor had a 10-s locking function, and if the same HCW took the liquid several times in $10 \mathrm{~s}$, only one HHE would be recorded. The information recorded by the identification badges was inputted into the computer through the card reader daily to obtain the HHEs of the HCWs automatically. Simultaneously, the system could get the consumption of ABHRs \& liquid soaps by multiplying the number of spraying of the dispensers by the amount of each ejection $(2 \mathrm{ml})$. The ranking of individual HHEs per bed day was fed back to the HCWs every month. As shown in Fig. 1.

\section{The type2 EHHMS}

From February 2019 to December 2019, the type2 EHHMS was used to monitor the HH of ICU HCWs. An additional file shows the technical parameters of type2 EHHMS (Additional file 1: The technical parameters. Part 2.). The system is an automated HH monitoring network. The bed zone recognizers were installed in each ICU bed. The dispensers of ABHRs or liquid soap with the bottle recognizers were installed near patient beds or sinks, and identity badges were worn for ICU HCWs. When the HCWs approached the bed zone, the badges would communicate with the bed zone recognizers. After $5 \mathrm{~s}$, the badges would light up, and a short beep would remind the $\mathrm{HH}$ three times. The HCWs needed to carry out $\mathrm{HH}$ and trigger the hydraulic recognizer to remove the alarm. If no $\mathrm{HH}$ after $20 \mathrm{~s}$ of reminding, the badge longly beeped, the red light went out, and the system recorded a no HHE. If there was no $\mathrm{HH}$ after leaving the bed, the badge's red glow flashed, and a short beep reminded the $\mathrm{HH}$ after the $160 \mathrm{~s}$. After the reminder, there was still no $\mathrm{HH}$ within $25 \mathrm{~s}$, and the system recorded it as no HHE. All data were automatically transmitted to the cloud access point (AP) installed on the ward ceiling, which uploaded the data to the background management system for storage and statistical analysis. Similar to the previous EHHMS, the system also recorded the consumption of ABHRs \& liquid soaps. The ranking of individual $\mathrm{HH}$ compliance rate was fed back to the HCWs monthly. As shown in Fig. 1.

\section{Monitoring indicators}

(1) HHEs per bed day = the actual number of HHEs / the actual total number of occupied bed days. The HHEs mean the times or number of $\mathrm{HH}$ actions. The ICU nurses recorded the actual number of occupied bed days at 12 o'clock each night, including the actual occupied temporary beds. Patients who died or were discharged before 12 o'clock in the evening after admission should also be counted.

(2) $\mathrm{HH}$ compliance rate $=$ the total number of actual HHEs/ the total number of $\mathrm{HH}$ moments $\times 100 \%$.

(3) Consumption of ABHRs \& liquid soaps per bed day = the total consumption of ABHRs \& liquid soaps/actual total number of occupied bed days.

\section{Data analysis}

The data were inputted into Excel 2016 to establish a database. The software Stata 15.1 (Stata Corporation, College Station, TX, US) was used for descriptive analysis, correlation analysis, and ITS analysis. First, an actest was performed to verify whether there was autocorrelation of time series data and determined the 


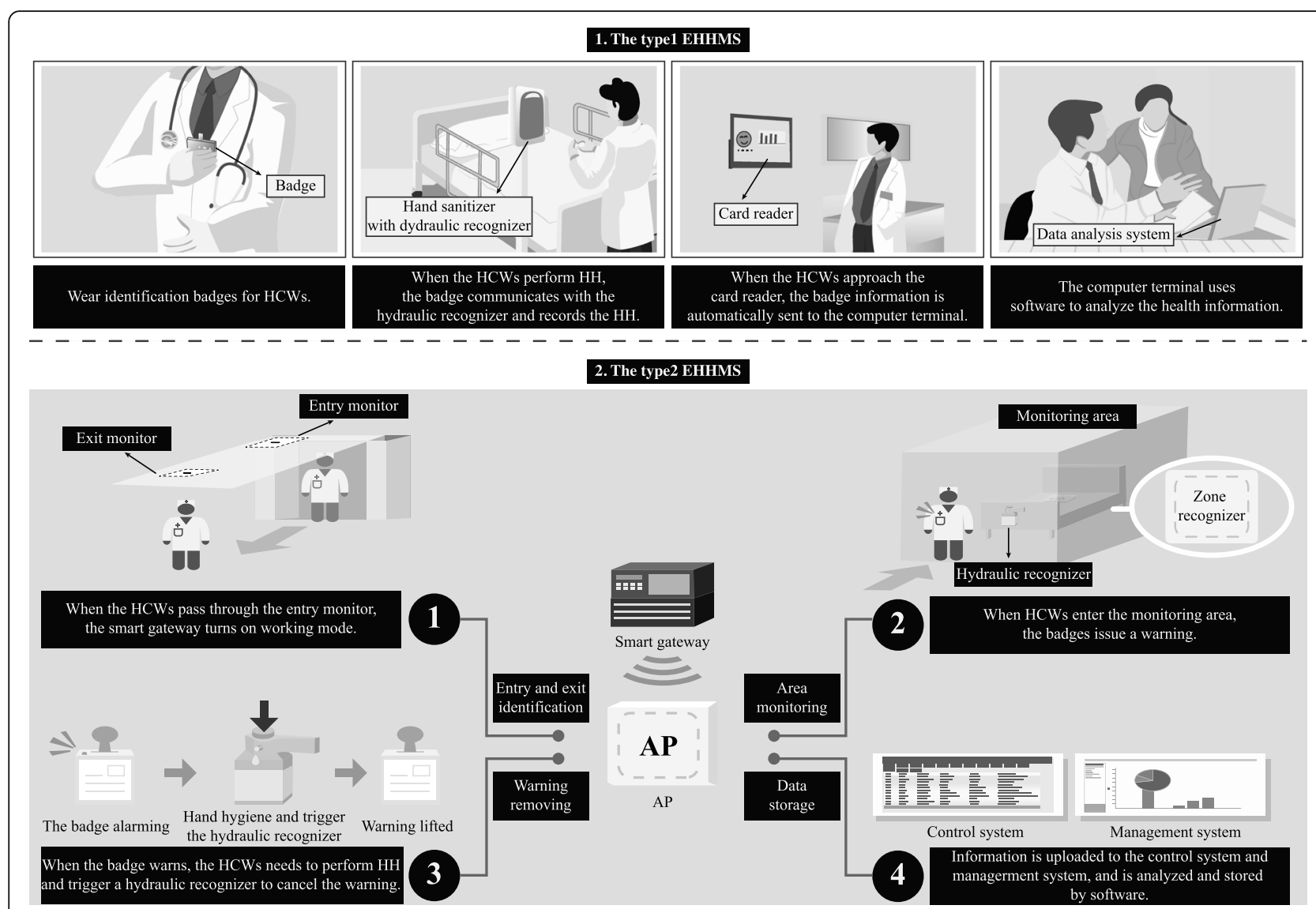

Fig. 1 The function flow chart of type1 and type2 EHHMS. Note. EHHMS, electronic hand hygiene monitoring system; HH, hand hygiene; HCW, healthcare worker; AP, cloud access point

maximum lag levels. Then monthly data were analyzed by the ITSA package in Stata software. The Newey-west model of ITSA was selected for analysis with the lags determined previously. This model provides Newey-west standard error to solve autocorrelation and possible heteroscedasticity of data based on the ordinary leastsquares regression. There were no control groups due to data limitations, and a single time series analysis model was used. The form of the model is as follows:

$$
\text { Y } \_ \text {}=\text { Beta } \_0+\text { Beta } \_1(T)+\text { Beta } \_2\left(X_{-} t\right)+\text { Beta } \_3\left(T X \_t\right)
$$

Y_t is the result variable measured at each interval point $t . T$ is the time since the study begins, $X_{-} t$ is the dummy variable representing the intervention ( 0 before the intervention, 1 otherwise), and TX_t is the interaction term. Beta_0 represents the intercept of the outcome variable. Beta_1 is the slope of the outcome variable before the intervention. Beta_2 represents the change in the outcome variable's level immediately after the introduction of the intervention (compared to the counterfactual case). Beta_3 represents the difference in outcome variable slope before and after the intervention.
Therefore, the significant $p$ values in Beta_2 indicated immediate intervention effects, or intervention effects over time in Beta_3.

The continuous variables accord with normal distribution were present as the means \pm standard deviation (SD). Frequencies and percentages described the categorical variables, and the comparisons between the groups were conducted by a chi-square test or Fisher's exact probability method. Statistical significance was observed at an $\alpha$ level of 0.05 .

\section{Results}

From March 2017 to December 2019, there were 1787 inpatients in the ICU, and the length of stay was 7138 days. There were $46 \mathrm{HCW}$ in the ICU. To maintain the ICU's workload, the number of HCWs remained stable, even if three nurses and one doctor changed during the study period. A total of 6253 times of $\mathrm{HH}$ moments and 4377 times of HHEs were observed by direct observation, and the total $\mathrm{HH}$ compliance rate was $70.00 \%$. The HHEs detected by EHHMS were 425,602 times, 59.37 times per bed day. The total consumption of ABHRs \& liquid soaps was $847,137 \mathrm{ml}, 118.2 \mathrm{ml}$ per bed day. 
According to the actest test, the maximum lag order was 1 for the $\mathrm{HH}$ compliance rate, the number of HHEs per bed day, and HH products' consumption per bed day. Therefore, the Newey-west model, with the lag order of 1 , was used to analyze the time-series data. The results showed that the $\mathrm{HH}$ compliance rate in the first stage increased by $0.250 \%$ per month. In March 2018, the first month of the use of the type1 EHHMS, the $\mathrm{HH}$ compliance rate of HCWs increased by $1.667 \%$. It then fell at a rate of $0.115 \%$ per month (relative to the first stage), but the difference was not statistically significant. In the first month using the type 2 system, the $\mathrm{HH}$ compliance rate increased immediately by $12.324 \%$ and then increased at a rate of $1.242 \%$ per month relative to the second stage, as shown in Table 1 and Fig. 2.

In February 2019, when the type2 system was introduced, the HHEs per bed day and the consumption of ABHRs \& liquid soaps per bed day all increased immediately by 13.565 times/bed day and $26.286 \mathrm{ml} /$ bed day, respectively. Afterward, they increased by 1.829 times/ bed day and $4.571 \mathrm{ml} /$ bed day over time, respectively, as shown in Table 2-3 and Fig. 3, 4, 5.

Spearman correlation test showed that the HH compliance rate from direct observation was correlated with HHEs per bed day $(r=0.956, P<0.001)$ and consumption of ABHRs \& liquid soaps per bed day $(r=0.904, P<$ 0.001 ), respectively. In the third stage, the $\mathrm{HH}$ compliance rate of 1,4 , and 5 of "the WHO's five $\mathrm{HH}$ moments" detected by the EHHMS was $77.75 \%(239,494 /$ 308019), which was lower than $89.16 \%(1112 / 1247)$ observed by the direct observation method, and the difference was statistically significant.

\section{Discussion}

$\mathrm{HH}$ promotion is an essential part of HAIs control. The strategies to promote $\mathrm{HH}$ in the guidelines issued by WHO included changing the medical institutions' cultural environment, providing accessible $\mathrm{HH}$ products, training and education of $\mathrm{HCWs}$, workplace reminder signs, and $\mathrm{HH}$ monitoring \& feedback [4]. Monitoring \& feedback is one of the essential and standard methods in the multi-mode promotion strategy of $\mathrm{HH}$. The purpose of monitoring is to obtain the status of $\mathrm{HH}$ compliance of HCWs and assess interventions' effectiveness. However, only monitoring does not improve $\mathrm{HH}$ compliance among HCWs; it must complement HH data's feedback. In the three stages of this study, the monitor methods and the contents of the feedback were different. However, the frequencies of feedback were identical, which all were monthly feedback. To remove the original trend of the outcome variables before the interventions, we applied the ITS analysis method.

The research design of ITS is regarded as the most robust quasi-experimental design. Because the design fully considered and balanced the outcome variables' variation trend before the intervention, relatively stable results could be obtained even if no control groups were set. According to the literature $[18,19]$, the $\mathrm{HH}$ compliance rate trend is often seasonal and self-correlation. The conventional statistical methods can not be suitable for analysis, and the application of ITS analysis can effectively solve these problems. In the first stage, the direct observation method was adopted for monitoring, and the monitoring results were fed back monthly. The $\mathrm{HH}$ compliance rate of HCWs showed an increasing trend of $0.250 \%$ per month. When the type1 EHHMS was introduced in March 2018, there was no significant increase in the $\mathrm{HH}$ compliance rate trend of HCWs compared to the first stage. The outcome indicated that the type1 EHHMS had no significant difference with the direct observation method in promoting the HCWs' $\mathrm{HH}$. The reason may be that HH's feedback method was not significantly different from the first stage, both of which were monthly feedback. However, the $\mathrm{HH}$ compliance rate of HCWs in the first month using the type2 EHHMs increased by $13.324 \%$ immediately and increased by $1.242 \%$ over time. Although the $\mathrm{HH}$ data were fed back monthly in the third stage, the type2 EHHMS can immediately remind HCWs to carry out $\mathrm{HH}$. The monitoring result indicated that this real-time reminder was beneficial to improve the $\mathrm{HH}$ of HCWs. It had been reported that EHHMS with real-time reminder

Table 1 The variation of hand hygiene compliance rate in the three stages obtained by the direct observation method

\begin{tabular}{|c|c|c|c|c|c|c|}
\hline HHCR & Coef. & Ne Wey-West Std. Err. & $t$ & $P>|t|$ & {$[95 \% \mathrm{Cl}]$} & \\
\hline$-t$ & .250 & .1060 & 2.36 & 0.026 & .033 & .467 \\
\hline _x2018m3 & 1.667 & 1.885 & 0.88 & 0.384 & -2.194 & 5.528 \\
\hline _x_t2018m3 & -.115 & .254 & -0.45 & 0.654 & -.635 & .405 \\
\hline _x2019m2 & 12.324 & 3.152 & 3.91 & 0.001 & 5.867 & 18.780 \\
\hline _x_t2019m2 & 1.242 & .440 & 2.82 & 0.009 & .341 & 2.144 \\
\hline _cons & 59.281 & .742 & 79.89 & 0.000 & 57.761 & 60.801 \\
\hline
\end{tabular}

Note. HHCR hand hygiene compliance rate, Coef coefficient, Std. Err. standard error, $C l$ confidence interval, _t time since the start of the study, $m$ month, _ $x$ (trperiod) dummy variable which representing the intervention periods (preintervention periods 0 , otherwise 1$)$, $\quad x \_t\left(\right.$ trperiod) the interaction of _x and $\_t$; cons, constant 


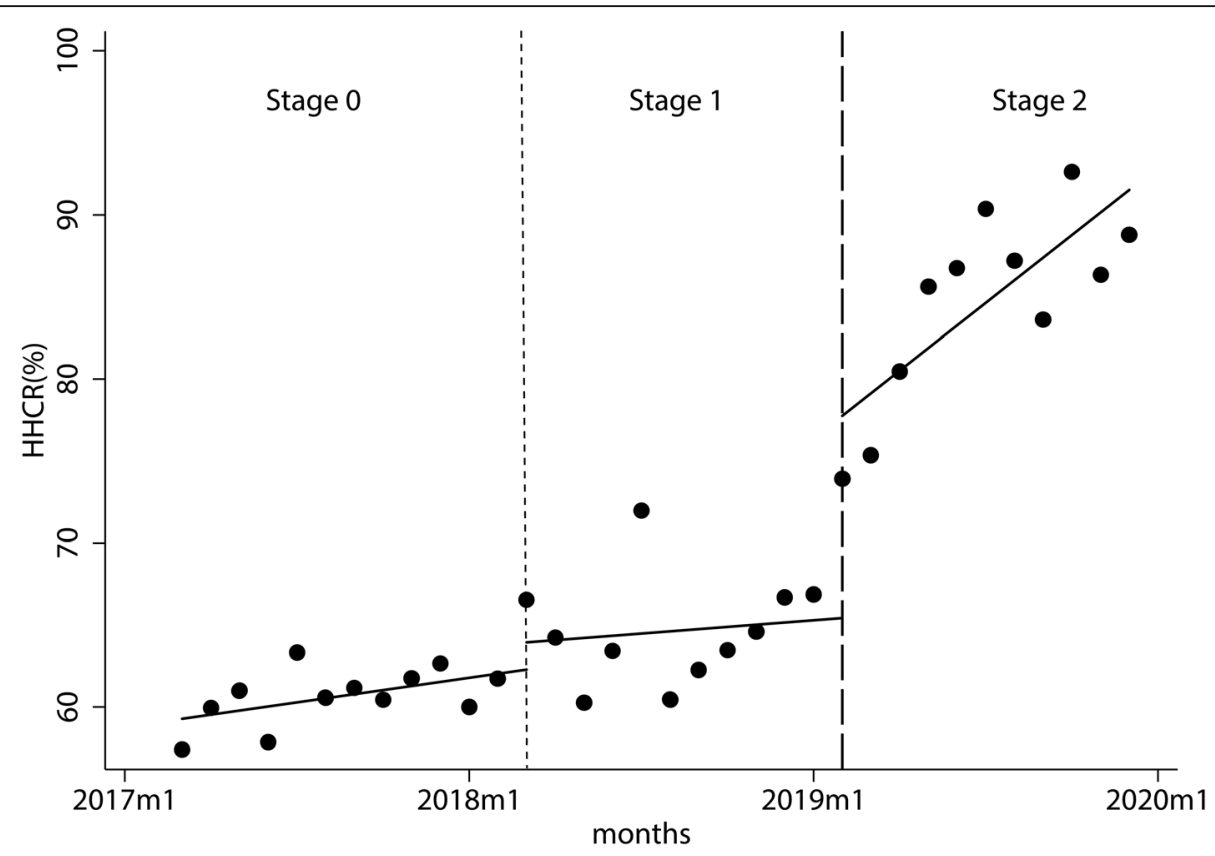

Fig. 2 The variation of hand hygiene compliance rate in the three stages obtained by the direct observation method. The monthly HHCR from Mar. 2017 to Dec. 2019 obtained by the direct observation method. The black spots show the actual HHCR, and the full line shows the predicted trend of the HHCR. The short dash vertical line represents the introduction of the type1 EHHMS (Mar. 2018), and the long dash vertical line depicts the application of the type2 EHHMS (Feb. 2019). The two vertical lines divide the time into three stages, which are stage 0, stage 1, and stage 2. Note. HHCR, hand hygiene compliance rate; $m$, month

and feedback function could promote the $\mathrm{HH}$ of $\mathrm{HCWs}$ $[12,20-22]$, which is consistent with the results of this study.

In this study, some advantages of EHHMS over the direct observation method were found: 1 . It is more comprehensive and can monitor the $\mathrm{HH}$ around the clock [23, 24]. In the second and third stages, the direct observation method only observed 3133 HHEs, while the number of HHEs monitored by the EHHMS was 425, 602, which was much higher than the direct observation method. 2. The type2 EHHMS has real-time reminders and feedback functions, which can better improve the $\mathrm{HH}$ compliance of HCWs. 3. The EHHMS can reduce the influence of the Hawthorne effect. In the third stage, the $\mathrm{HH}$ compliance rate (before and after contact with the patient, after contact with the patient's surroundings) monitored by the type2 EHHMS was far lower than the rate observed. One of the primary reasons may be that the Hawthorne effect of EHHMS was different from direct observation [13]. Although with the EHHMS, HCWs would feel monitored at the beginning because of wearing identity badges. However, as time went by, HCWs would get used to wearing identity badges, and the Hawthorne effect would gradually decrease. Vaisman A et al. [25] found that the number of HHEs recorded by EHHMS was 2.5 times higher when the observer was present than absent, and the difference may be attributed to the Hawthorne effect. Besides, the EHHMS was not as accurate as of the direct observation method in the identification of $\mathrm{HH}$ indicators [26], so more $\mathrm{HH}$ moments were recorded [27].

However, EHHMS also has some limitations [12, 16, 26], such as the inability to monitor the correctness of $\mathrm{HH}$, which usually costs a lot, and the failure to follow the five $\mathrm{HH}$ moments recommended by WHO adequately. The type2 system in this study, like many systems [24, 28],

Table 2 The variation of hand hygiene events per bed day in stages 1 and 2

\begin{tabular}{|c|c|c|c|c|c|c|}
\hline HHEs & Coef. & Ne Wey-West Std. Err. & $t$ & $P>|t|$ & {$[95 \% \mathrm{Cl}]$} & \\
\hline$-t$ & .015 & .331 & 0.04 & 0.965 & -.681 & .710 \\
\hline _x2019m2 & 13.565 & 3.940 & 3.44 & 0.003 & 5.287 & 21.843 \\
\hline _x_t2019m2 & 1.829 & .591 & 3.09 & 0.006 & .587 & 3.071 \\
\hline _cons & 76.565 & 2.368 & 32.33 & 0.000 & 71.589 & 81.540 \\
\hline
\end{tabular}

Note. HHEs hand hygiene events, Coef coefficient, Std. Err. standard error, $\mathrm{Cl}$ confidence interval, $t$ time since the start of the study, $m$ month, $x($ trperiod) dummy variable which representing the intervention periods (preintervention periods 0 , otherwise 1$)$, $x_{-} t\left(\right.$ trperiod) the interaction of $\_x$ and $\_t$, cons constant 
Table 3 Changes in consumption of ABHR and liquid soap per bed day in stages 1 and 2

\begin{tabular}{|c|c|c|c|c|c|c|}
\hline HHPC & Coef. & Ne Wey-West Std. Err. & $t$ & $P>|t|$ & {$[95 \% \mathrm{Cl}]$} & \\
\hline$-t$ & -.721 & 1.094 & -0.66 & 0.518 & -3.019 & 1.577 \\
\hline$-\times 2019 m 2$ & 26.285 & 8.470 & 3.10 & 0.006 & 8.490 & 44.079 \\
\hline _x_t2019m2 & 4.571 & 1.446 & 3.16 & 0.005 & 1.533 & 7.609 \\
\hline _cons & 158.496 & 8.127 & 19.50 & 0.000 & 141.420 & 175.571 \\
\hline
\end{tabular}

Note. HHPC hand hygiene product consumption, Coef coefficient, Std. Err. standard error, $C l$ confidence interval, $t$ time since the start of the study, $m$ month, _x(trperiod), dummy variable which representing the intervention periods (preintervention periods 0 , otherwise 1 ), $\_x \_t\left(\right.$ trperiod), the interaction of _ $x$ and $\_t$; _cons, constant

can only detect 1,4 , and 5 of the five WHO's $\mathrm{HH}$ moments, but not 2 and 3 . However, it has been reported that it can also be used as an alternative to $\mathrm{HH}$ compliance monitoring $[29,30]$, which can detect $80-85 \%$ of $\mathrm{HH}$ indicators [31, 32].

The EHHMS used in this study can monitor the number of HHEs and the consumption of ABHRs \& liquid soaps per bed day. At present, many EHHMSs have this function $[24,28]$. Although it can not directly calculate the $\mathrm{HH}$ compliance rate, it can also reflect the $\mathrm{HH}$ compliance of HCWs from one side. In this study, the ITS analysis was performed to analyze the number of HHEs and $\mathrm{HH}$ product's consumption in the second and third stages. The findings were consistent with the $\mathrm{HH}$ compliance rate trend of HCWs obtained by direct observation. Furthermore, the correlation analysis results also showed that the $\mathrm{HH}$ compliance rate obtained by direct observation was positively correlated with the HHEs per bed day and $\mathrm{HH}$ product's consumption per bed day obtained by EHHMS. It was suggesting that the results of EHHMS could be used to replace the direct observation method to evaluate the $\mathrm{HH}$ compliance of HCWs.

\section{Study limitations}

There are some limitations to this study: 1. ITS design belongs to a quasi-experimental study. Although the research variables' trend was controlled before the interventions, other confounding factors affecting the change of research variables could not be considered. 2. It has been reported that the compliance of HCWs wearing identification badges is one of the obstacles to the use of EHHMS [33]. However, in this study, supervisors were set up to urge HCWs to wear identification badges. Therefore, compliance with the spontaneous application of identification badges by HCWs could not be monitored.

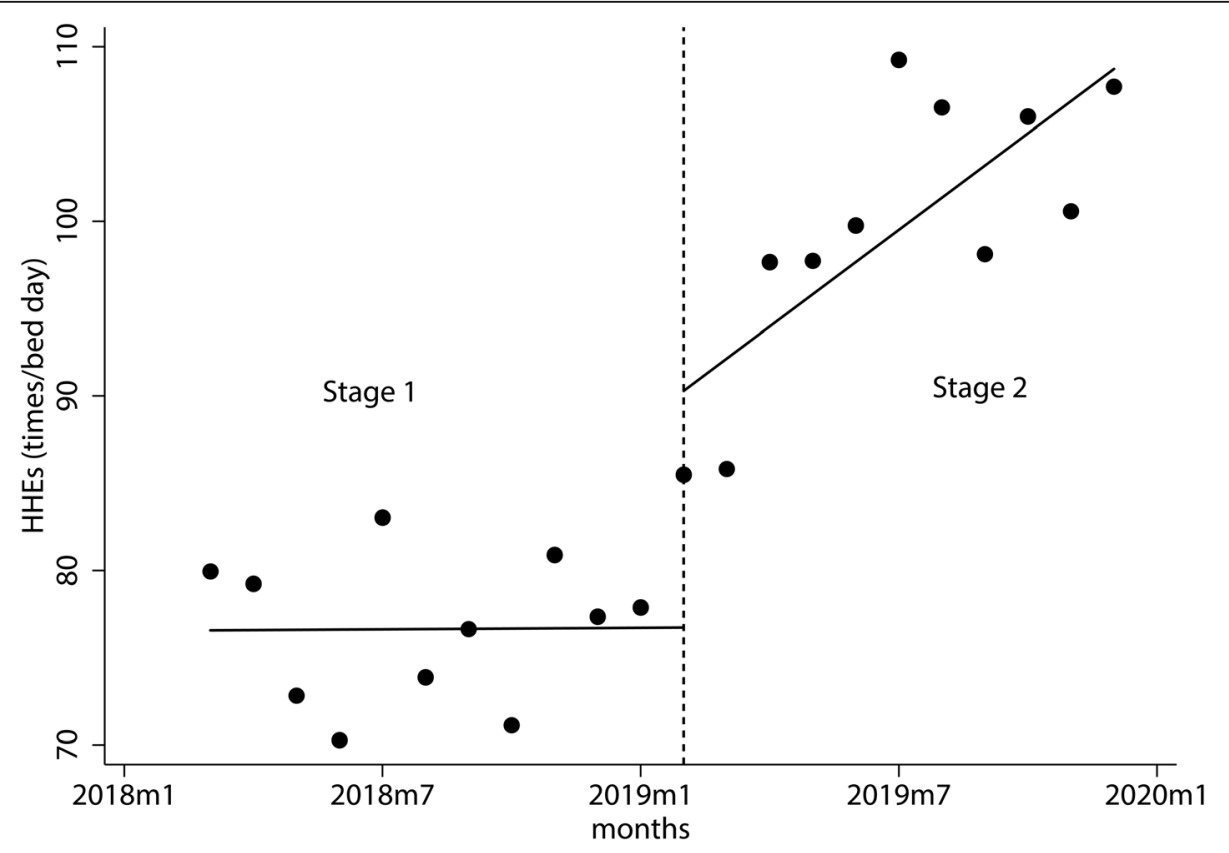

Fig. 3 The variation of hand hygiene events per bed day in stages 1 and 2. The monthly HHEs per bed day from Mar. 2018 to Dec. 2019 obtained by EHHMS. The black spots show the actual HHEs per bed day, and the full line shows the predicted trend of the HHEs per bed day. The short dash vertical line depicts the application of the type2 EHHMS (Feb. 2019). The vertical lines divide the time into two stages, which are stage 1 and stage 2. Note. HHEs, hand hygiene events; m, month 


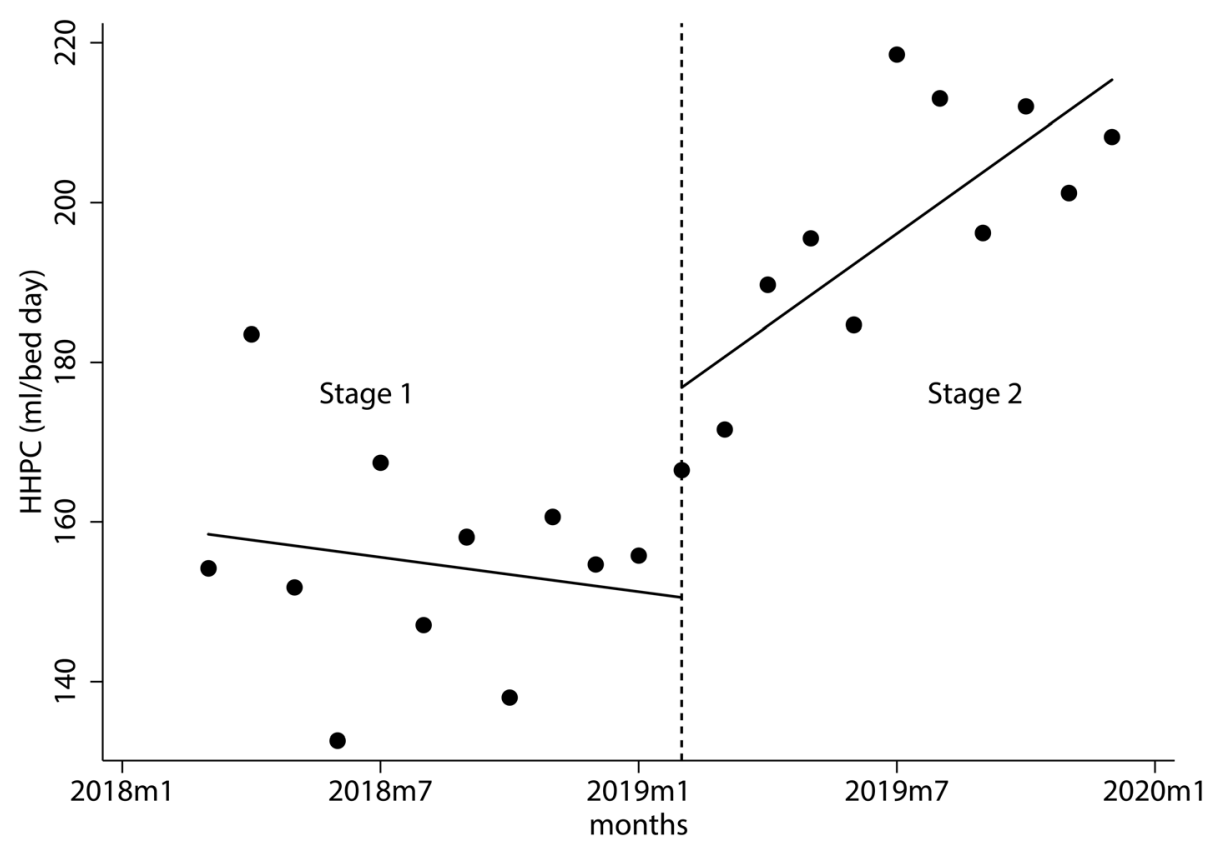

Fig. 4 Changes in consumption of ABHR and liquid soap per bed day in stages 1 and 2. The monthly hand hygiene product consumption from Mar. 2018 to Dec. 2019 obtained by EHHMS. The black spots show the actual hand hygiene product consumption, and the full line shows the predicted trend of the hand hygiene product consumption. The short dash vertical line depicts the application of the type2 EHHMS (Feb. 2019). The vertical lines divide the time into two stages, which are stage 1 and stage 2. Note. HHPC, hand hygiene product consumption; m, month

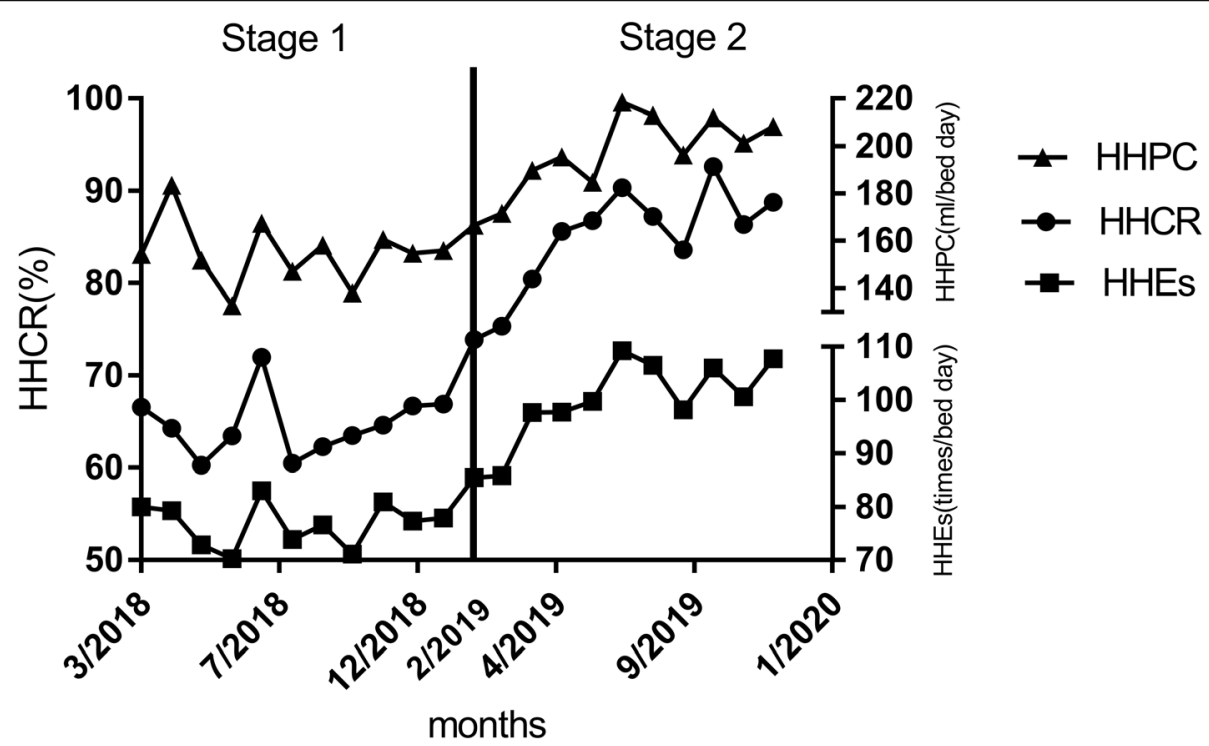

Fig. 5 The variation of hand hygiene compliance rate, hand hygiene events per bed day, and hand hygiene product consumption per bed day in stages 1 and 2. The black spots line shows the hand hygiene compliance rate, the triangle spots line shows the hand hygiene product consumption per bed day, and the square spots line shows the hand hygiene events in stages 1 and 2. The solid vertical line depicts the application of the type2 EHHMS (Feb. 2019). The vertical lines divide the time into two stages, which are stage 1 and stage 2. Note. HHEs, hand hygiene events; HHCR, hand hygiene compliance rate; HHPC, hand hygiene product consumption 


\section{Conclusions}

In summary, the number of HHEs and consumption of $\mathrm{HH}$ products monitored by the EHHMS in ICU can well reflect the $\mathrm{HH}$ compliance of $\mathrm{HCW}$. $\mathrm{HH}$ compliance of HCWs can be improved by $\mathrm{HH}$ monitoring and feedback. The EHHMS, with instant reminder and feedback function, can promote $\mathrm{HH}$ more obviously. At present, the EHHMS cannot adequately detect the WHO's five $\mathrm{HH}$ moments. A more intelligent and accurate EHHMS, such as using the camera with artificial intelligence image recognition to identify the HCW's $\mathrm{HH}$ moments and HHEs, is worth our expectations.

\section{Supplementary Information}

The online version contains supplementary material available at https://doi. org/10.1186/s12879-020-05748-3.

Additional file 1. The technical parameters. Part 1. The type1 EHHMS equipment technical parameters. Part 2. The type2 EHHMS equipment technical parameters.

\section{Abbreviations}

EHHMSs: Electronic hand hygiene monitoring systems; $\mathrm{HH}$ : Hand hygiene; HCWs: Healthcare workers; ICU: Intensive care unit; ITS: Interrupted time series; HHCR: Hand hygiene Compliance rate; HHEs: Hand hygiene events; HAl: Healthcare-associated infection; ABHRs: Alcohol-based hand rubs; Coef: Coefficient; Std. Err.: Standard error; Cl: Confidence interval; m: Month

\section{Acknowledgments}

We want to thank the ICU HCWs of Shenzhen Hospital of the Chinese Sciences Academy for supporting and cooperating with our research.

\section{Authors' contributions}

$Z X$ is responsible for the study design, data analysis, interpretation of the data, statistical analysis, and the article's drafting. MLF, WQF, CYW, and LXF are responsible for the implementation of the study, collection of data, and final approval. WDL and XLH are responsible for interpreting the data, critical revision of the article for important intellectual content, and final approval. The authors read and approved the final manuscript.

\section{Funding}

None.

\section{Availability of data and materials}

The data used in the study was available from the department of nosocomial infection control of the Shenzhen Hospital of the University of Chinese Academic of Science.

\section{Ethics approval and consent to participate}

The ethics committee of the Shenzhen hospital University of the Chinese Academy of Sciences approved the study. All participants had signed informed consent.

\section{Consent for publication}

Not applicable.

\section{Competing interests}

All authors declare that they have no competing interests.

\section{Author details}

${ }^{1}$ Department of Nosocomial Infection Control, Shenzhen Hospital, University of Chinese Academy of Sciences, Shenzhen 518106, Guangdong, China. ${ }^{2}$ Inspection center, Guangming District Center for Disease Control and Prevention, Shenzhen, Guangdong, China.
Received: 24 May 2020 Accepted: 27 December 2020

Published online: 11 January 2021

\section{References}

1. Stella SA, Stace RJ, Knepper BC, Reese SM, Keniston A, Burden M, Young HL. The effect of eye images and a social norms message on healthcare provider hand hygiene adherence. Infect Control Hosp Epidemiol. 2019; 40(7):748-54.

2. Pittet D, Allegranzi B, Sax H, Dharan S, Pessoa-Silva CL, Donaldson L, Boyce $J M$. Evidence-based model for hand transmission during patient care and the role of improved practices. Lancet Infect Dis. 2006;6(10):641-52.

3. Boyce JM, Polgreen PM, Monsalve M, Macinga DR, Arbogast JW. Frequency of use of alcohol-based hand rubs by nurses: a systematic review. Infect Control Hosp Epidemiol. 2017;38(2):189-95.

4. Organization WH, Safety WP. WHO guidelines on hand hygiene in health care. Geneva: World Health Organization; 2009.

5. Grayson ML, Stewardson AJ, Russo PL, Ryan KE, Olsen KL, Havers SM, Greig S, Cruickshank M. Hand hygiene a, the National Hand Hygiene I: effects of the Australian National Hand Hygiene Initiative after 8 years on infection control practices, healthcare worker education, and clinical outcomes: a longitudinal study. Lancet Infect Dis. 2018;18(11):1269-77.

6. Barnes SL, Morgan DJ, Harris AD, Carling PC, Thom KA. Preventing the transmission of multidrug-resistant organisms: modeling the relative importance of hand hygiene and environmental cleaning interventions. Infect Control Hosp Epidemiol. 2014;35(9):1156-62.

7. Erasmus V, Daha TJ, Brug H, Richardus JH, Behrendt MD, Vos MC, van Beeck EF. Systematic review of studies on compliance with hand hygiene guidelines in hospital care. Infect Control Hosp Epidemiol. 2010;31(3):283-94

8. Neo JR, Sagha-Zadeh R, Vielemeyer O, Franklin E. Evidence-based practices to increase hand hygiene compliance in health care facilities: an integrated review. Am J Infect Control. 2016;44(6):691-704.

9. Price L, MacDonald J, Gozdzielewska L, Howe T, Flowers P, Shepherd L, Watt $Y$, Reilly J. Interventions to improve healthcare workers' hand hygiene compliance: a systematic review of systematic reviews. Infect Control Hosp Epidemiol. 2018;39(12):1449-56.

10. Alshehari AA, Park S, Rashid H. Strategies to improve hand hygiene compliance among healthcare workers in adult intensive care units: a mini systematic review. J Hosp Infect. 2018;100(2):152-8.

11. Jeanes A, Coen PG, Drey NS, Gould DJ. Moving beyond hand hygiene monitoring as a marker of infection prevention performance: development of a tailored infection control continuous quality improvement tool. Am J Infect Control. 2020:48(1):68-76.

12. Edmisten C, Hall C, Kernizan L, Korwek K, Preston A, Rhoades E, Shah S, Spight L, Stradi S, Wellman S, et al. Implementing an electronic hand hygiene monitoring system: lessons learned from community hospitals. Am J Infect Control. 2017:45(8):860-5.

13. Doll ME, Masroor N, Cooper K, Trimmer T, Pryor R, Auricchio J, ArmstrongNovak JD, Stevens MP, Bearman G. A comparison of the accuracy of two electronic hand hygiene monitoring systems. Infect Control Hosp Epidemiol. 2019;40(10):1194-7.

14. Marra AR, Edmond MB. New technologies to monitor healthcare worker hand hygiene. Clin Microbiol Infect. 2014;20(1):29-33.

15. Storey SJ, FitzGerald G, Moore G, Knights E, Atkinson S, Smith S, Freeman $\mathrm{O}$, Cryer P, Wilson AP. Effect of a contact monitoring system with immediate visual feedback on hand hygiene compliance. J Hosp Infect. 2014;88(2):84-8.

16. Ward MA, Schweizer ML, Polgreen PM, Gupta K, Reisinger HS, Perencevich EN. Automated and electronically assisted hand hygiene monitoring systems: a systematic review. Am J Infect Control. 2014:42(5):472-8.

17. Pong S, Holliday P, Fernie G. Effect of electronic real-time prompting on hand hygiene behaviors in health care workers. Am J Infect Control. 2018; 46(7):768-74.

18. Wiemken $T L$, Hainaut L, Bodenschatz H, Varghese R. Hand hygiene compliance surveillance with time series anomaly detection. Am J Infect Control. 2019;47(12):1449-52

19. Luangasanatip N, Hongsuwan M, Limmathurotsakul D, Lubell Y, Lee AS, Harbarth S, Day NPJ, Graves N, Cooper BS: Comparative efficacy of interventions to promote hand hygiene in hospital: systematic review and network meta-analysis. BMJ (Clinical research ed). 2015. 
20. Armellino D, Hussain E, Schilling ME, Senicola W, Eichorn A, Dlugacz Y Farber BF. Using high-technology to enforce low-technology safety measures: the use of third-party remote video auditing and real-time feedback in healthcare. Clin Infect Dis. 2012:54(1):1-7.

21. Fisher DA, Seetoh T, Oh May-Lin H, Viswanathan S, Toh Y, Yin WC, Siw Eng L, Yang TS, Schiefen S, Je M, et al. Automated measures of hand hygiene compliance among healthcare workers using ultrasound: validation and a randomized controlled trial. Infect Control Hosp Epidemiol. 2013;34(9):919-28.

22. Boscart VM, McGilton KS, Levchenko A, Hufton G, Holliday P, Fernie GR. Acceptability of a wearable hand hygiene device with monitoring capabilities. J Hosp Infect. 2008;70(3):216-22

23. Srigley JA, Lightfoot D, Fernie G, Gardam M, Muller MP. Hand hygiene monitoring technology: protocol for a systematic review. Syst Rev. 2013;2:101.

24. McKay KJ, Shaban RZ, Ferguson P. Hand hygiene compliance monitoring: do video-based technologies offer opportunities for the future? Infect Dis Health. 2020.

25. Vaisman A, Bannerman G, Matelski J, Tinckam K, Hota SS. Out of sight, out of mind: a prospective observational study to estimate the duration of the Hawthorne effect on hand hygiene events. BMJ Qual Saf. 2020;29(11): bmjqs-2019-010310

26. Levin PD, Razon R, Schwartz C, Avidan A, Sprung CL, Moses AE, Benenson S. Obstacles to the successful introduction of an electronic hand hygiene monitoring system, a cohort observational study. Antimicrob Resist Infect Control. 2019:8:43

27. Swoboda SM, Earsing K, Strauss K, Lane S, Lipsett PA. Electronic monitoring and voice prompts improve hand hygiene and decrease nosocomial infections in an intermediate care unit. Crit Care Med. 2004;32(2):358-63.

28. Al Salman JM, Hani S, de Marcellis-Warin N, Isa SF. Effectiveness of an electronic hand hygiene monitoring system on healthcare workers' compliance to guidelines. J Infect Public Health. 2015;8(2):117-26.

29. Masroor N, Doll M, Stevens M, Bearman G. Approaches to hand hygiene monitoring: from low to high technology approaches. Int J Infect Dis. 2017; 65:101-4.

30. Lebovic G, Siddiqui N, Muller MP. Predictors of hand hygiene compliance in the era of alcohol-based hand rinse. J Hosp Infect. 2013;83(4):276-83.

31. Boscart VM, Levchenko Al, Fernie GR. Defining the configuration of a hand hygiene monitoring system. Am J Infect Control. 2010;38(7):518-22.

32. Cheng VC, Tai JW, Ho SK, Chan JF, Hung KN, Ho PL, Yuen KY. Introduction of an electronic monitoring system for monitoring compliance with moments 1 and 4 of the WHO "my 5 moments for hand hygiene" methodology. BMC Infect Dis. 2011;11:151.

33. Conway $L$. Challenges in implementing electronic hand hygiene monitoring systems. Am J Infect Control. 2016;44(5 Suppl):e7-e12.

\section{Publisher's Note}

Springer Nature remains neutral with regard to jurisdictional claims in published maps and institutional affiliations.

Ready to submit your research? Choose BMC and benefit from:

- fast, convenient online submission

- thorough peer review by experienced researchers in your field

- rapid publication on acceptance

- support for research data, including large and complex data types

- gold Open Access which fosters wider collaboration and increased citations

- maximum visibility for your research: over $100 \mathrm{M}$ website views per year

At $\mathrm{BMC}$, research is always in progress.

Learn more biomedcentral.com/submissions 